\title{
Use of cystatin C-based estimations of glomerular filtration rate in patients with type 2 diabetes
}

\author{
R. A. Chudleigh • R. L. Ollerton • G. Dunseath • \\ R. Peter • J. N. Harvey $\cdot$ S. Luzio $\cdot$ D. R. Owens
}

Received: 10 January 2009 / Accepted: 3 April 2009/Published online: 9 May 2009

(C) Springer-Verlag 2009

\begin{abstract}
Aims/hypothesis The Modification of Diet in Renal Disease (MDRD) equation has recognised limitations when using estimated GFR in persons at risk of chronic kidney disease. Equations based on cystatin $\mathrm{C}$ provide an alternative method. We compared performance of the MDRD equation with a selection of cystatin C-based formulae for estimation of GFR in normoalbuminuric patients with type 2 diabetes. Methods Estimated GFR was calculated using the MDRD equation and the cystatin $\mathrm{C}$ formulae proposed by several investigator teams. Isotopic GFR was measured using plasma clearance of ${ }^{51} \mathrm{Cr}$-EDTA.

Results We studied 106 participants, of whom 83 (78\%) were men with the following characteristics, mean (SD): age 61 (9) years, $\mathrm{HbA}_{1 \mathrm{c}} 7.10$ (1.27)\%, creatinine 89.0 (12.7) $\mu \mathrm{mol} / 1$, cystatin C $0.859(0.234) \mathrm{mg} / \mathrm{l}$ and isotopic GFR 104.5 (20.1) $\mathrm{ml} \mathrm{min}^{-1} 1.73 \mathrm{~m}^{-2}$. MDRD estimated GFR was 77.4 (13.6) $\mathrm{ml} \mathrm{min}^{-1} 1.73 \mathrm{~m}^{-2}(p<0.05$ for difference from isotopic GFR). Cystatin C-based calculations of estimated GFR were: Perkins 124.5 (31.8), Rule 90.0 (30.0), Stevens (age) 96.0 (30.4) and Stevens (creatinine) $85.6(19.0) \mathrm{ml}$
\end{abstract}

R. A. Chudleigh $(\bowtie) \cdot$ G. Dunseath $\cdot$ R. Peter $\cdot$ S. Luzio $\cdot$

D. R. Owens

Diabetes Research Unit, Llandough University Hospital,

Penlan Road, Llandough, Penarth,

Cardiff CF64 2XX, UK

e-mail: rachudleigh@hotmail.com

R. L. Ollerton

School of Computing and Mathematics,

University of Western Sydney,

Penrith South DC, NSW, Australia

J. N. Harvey

Department of Medicine, Wrexham Maelor Hospital,

Wrexham, UK $\min ^{-1} 1.73 \mathrm{~m}^{-2}$ ( $p<0.05$ for difference with isotopic GFR). For Arnal's, MacIsaac's and Tan's formulae cystatin-C estimated GFR were 101.7 (34.8), 102.1 (27.0) and 101.6 (27.8) $\mathrm{ml} \mathrm{min}^{-1} 1.73 \mathrm{~m}^{-2}$, respectively ( $p=\mathrm{NS}$ for difference with isotopic GFR). Cystatin C-based formulae were less biased and, with the exception of Perkins' formula, more accurate to within $10 \%$ of isotopic GFR than MDRD.

Conclusions/interpretation Performance of cystatin C equations was superior to MDRD in normoalbuminuric patients with type 2 diabetes. These results support further evaluation of cystatin $\mathrm{C}$ for estimation of GFR in persons at risk of chronic kidney disease.

Keywords Cystatin C - eGFR - Estimated GFR - MDRD . Type 2 diabetes

\section{Abbreviation \\ MDRD Modification of Diet in Renal Disease}

\section{Introduction}

Strong evidence supports the need for early detection of diabetic nephropathy, when timely intervention can improve long-term outcome [1]. Currently, estimation of glomerular filtration rate (estimated GFR) derived from the Modification of Diet in Renal Disease (MDRD) formula [2] is recommended in the annual evaluation of all patients with type 2 diabetes [1]. However, this formula has well-known limitations [3]. Therefore, new alternatives that more accurately reflect early decline in kidney function are needed.

Cystatin C, a low molecular mass basic protein that is filtered at the glomerulus and then completely reabsorbed and catabolised by tubular cells, has emerged as a potential 
surrogate marker of GFR [4, 5]. Reports have suggested that the reciprocal of cystatin $\mathrm{C}$ is a more sensitive indicator of declining kidney function than estimated GFR [4]. Cystatin $\mathrm{C}$ is also reported to better predict longitudinal changes in GFR [4, 5]. Recently, several cystatin C-based formulae have been proposed for estimation of GFR [4, 69], some of which also incorporate age, sex and race [10].

This study was designed to compare the performance of GFR estimations obtained by cystatin C-based formulae with those obtained by the MDRD formula in predicting isotopically measured GFR in patients with type 2 diabetes and normoalbuminuria.

\section{Methods}

All participants in this study provided informed consent. Following an overnight fast anthropometric and biochemical measurements were made. Serum creatinine concentrations ( $\mu \mathrm{mol} / \mathrm{l}$ ) were determined using the Johnson \& Johnson dryslide system (Johnson \& Johnson, High Wycombe, UK). The laboratory reported that the coefficient of variation of the assay was $4.2 \%$ at a creatinine concentration of $103 \mu \mathrm{mol} / 1$ and $1.92 \%$ at a creatinine concentration of $516 \mu \mathrm{mol} / 1$. Cystatin $\mathrm{C}$ concentrations $(\mathrm{mg} / \mathrm{l})$ were determined using a human cystatin C colorimetric immunoassay (Quantikine, R\&D Systems Europe, Abingdon, UK), with a reported coefficient of variation of $7.0 \%$. Isotopic GFR $\left(\mathrm{ml} \mathrm{min}^{-1} 1.73 \mathrm{~m}^{-2}\right)$ was measured by the single injection plasma clearance of $1 \mathrm{MBq}$ of ${ }^{51} \mathrm{Cr}$-EDTA; the four sample method used has previously been validated against plasma clearance determined by multiple sampling [11].

Estimation of GFR Estimated GFR was calculated using the abbreviated four-variable MDRD formula and seven other cystatin C-based formulae, as shown below, where eGFR stands for estimated GFR:

The abbreviated four-variable MDRD formula [2] was:

$$
\begin{aligned}
& \operatorname{eGFR}\left(\mathrm{ml} \mathrm{min} \min ^{-1} 1.73 \mathrm{~m}^{-2}\right)=186 \times[\text { serum creatinine } \\
& (\mu \mathrm{mol} / 1) / 88.4]^{-1.154} \times[\text { age }(\text { years })]^{-0.203} \\
& \times(0.742 \text { if female })
\end{aligned}
$$

The cystatin C-based formulae were:

Perkins et al. [4]:

$$
\operatorname{eGFR}\left(\mathrm{ml} \mathrm{min}-1.73 \mathrm{~m}^{-2}\right)=100 /(\text { cystatin } C)
$$

Arnal et al. [6]:

$$
\operatorname{eGFR}\left(\mathrm{ml} \mathrm{min}{ }^{-1} 1.73 \mathrm{~m}^{-2}\right)=74.835 /\left(\text { cystatin } \mathrm{C}^{1.333}\right)
$$

Rule et al. [7]:

$\operatorname{eGFR}\left(\mathrm{ml} \mathrm{min}^{-1} 1.73 \mathrm{~m}^{-2}\right)=66.8 /\left(\right.$ cystatin $\left.\mathrm{C}^{1.30}\right)$

MacIsaac et al. [8]:

$\operatorname{eGFR}\left(\mathrm{ml} \mathrm{min}-1.73 \mathrm{~m}^{-2}\right)=(84.6 /$ cystatin $\mathrm{C})-3.2$

Tan et al. [9]:

eGFR $\left(\mathrm{ml} \mathrm{min} \min ^{-1} 1.73 \mathrm{~m}^{-2}\right)=(87.1 /$ cystatin $\mathrm{C})-6.87$

Stevens et al. (cystatin C-age) [10]:

$$
\begin{aligned}
& \text { eGFR }\left(\mathrm{ml} \mathrm{min}^{-1} 1.73 \mathrm{~m}^{-2}\right)=127.7 /\left(\text { cystatin } \mathrm{C}^{1.17}\right) \\
& \times[\text { age }(\text { years })]^{-0.13} \times(0.91 \text { if female })
\end{aligned}
$$

Stevens et al. (cystatin C-creatinine) [10]:

$$
\begin{aligned}
& \text { eGFR }\left(\mathrm{ml} \mathrm{min}^{-1} 1.73 \mathrm{~m}^{-2}\right)=177.6 \times[\text { creatinine } \\
& (\mu \mathrm{mol} / 1 / 88.4)]^{-0.65} \times\left(\text { cystatin } \mathrm{C}^{-0.57}\right) \\
& \times[\text { age }(\text { years })]^{-0.20} \times(0.82 \text { if female })
\end{aligned}
$$

Statistical analysis In order to assess the performance of formulae, estimated GFR results were compared with isotopic GFR by means of two-tailed, paired and unpaired $t$ tests (confirmed by non-parametric equivalents for non-normal distributions as appropriate), and by Levene's test for equality of variance. All calculations were performed using SPSS (12.0.1; 2003; SPSS, Chicago, IL, USA). Results are presented as mean (SD) and mean $(95 \% \mathrm{CI})$ unless otherwise indicated. $p<0.05$ was taken to indicate statistical significance.

\section{Results}

A total of 106 patients participated in the study. The majority (83, i.e. $78 \%$ ) of participants were men. The group consisted of $104(98 \%)$ whites and two (2\%) persons of South Asian origin, with 67 members (63.2\%) newly diagnosed with type 2 diabetes.

The mean (SD) age of the study population was 60.9 (8.7) years, with BMI $31.14(6.53) \mathrm{kg} / \mathrm{m}^{2}$, fasting plasma glucose 8.09 (1.96) mmol/l, $\mathrm{HbA}_{1 \mathrm{c}} 7.10(1.27) \%$, serum creatinine $89.0(12.7) \mu \mathrm{mol} / \mathrm{l}$, cystatin C 0.859 (0.234) $\mathrm{mg} / \mathrm{l}$ and ${ }^{51} \mathrm{Cr}$-EDTA-measured isotopic GFR 104.5 (20.1) $\mathrm{ml} \mathrm{min}^{-1} 1.73 \mathrm{~m}^{-2}$.

Performance of the MDRD and cystatin C-based formulae for GFR are presented in Table 1. Performance was assessed in terms of bias (mean difference between 
Table 1 Performance of GFR estimation formulas

\begin{tabular}{|c|c|c|c|c|c|c|}
\hline \multirow[t]{2}{*}{ Formula } & \multirow[t]{2}{*}{ eGFR } & \multirow[t]{2}{*}{$\operatorname{Bias}^{\mathrm{b}}$} & \multirow[t]{2}{*}{$\operatorname{Bias}^{\mathrm{b}}(95 \% \mathrm{CI})$} & \multirow[t]{2}{*}{ Precision (SD of bias) } & \multicolumn{2}{|c|}{ Accuracy, \% $(95 \% \mathrm{CI})$} \\
\hline & & & & & $10 \%$ & $30 \%$ \\
\hline MDRD & $77.4(13.6)^{\mathrm{a}}$ & $-27.1(18.0)$ & $-30.6,-23.7$ & 18.0 & $10(4,16)$ & $65(56,74)$ \\
\hline Perkins & $124.5(31.8)^{\mathrm{a}}$ & $20.0(29.5)^{c}$ & $14.3,25.7$ & $29.5^{\mathrm{c}}$ & $21(13,29)$ & $64(55,73)$ \\
\hline Arnal & $101.7(34.8)$ & $-2.8(32.2)^{\mathrm{c}}$ & $-9.0,3.4$ & $32.2^{\mathrm{c}}$ & $30(21,39)^{\mathrm{c}}$ & $75(66,83)$ \\
\hline Rule & $90.0(30.0)^{\mathrm{a}}$ & $-14.5(28.4)^{\mathrm{c}}$ & $-20.0,9.1$ & $28.4^{\mathrm{c}}$ & $31(22,40)^{\mathrm{c}}$ & $68(59,77)$ \\
\hline MacIsaac & $102.1(27.0)$ & $-2.4(26.0)^{\mathrm{c}}$ & $-7.4,2.6$ & $26.0^{\mathrm{c}}$ & $34(25,43)^{\mathrm{c}}$ & $85(78,92)^{\mathrm{c}}$ \\
\hline Tan & $101.6(27.8)$ & $-2.9(26.6)^{\mathrm{c}}$ & $-8.0,2.2$ & $26.6^{\mathrm{c}}$ & $34(25,43)^{\mathrm{c}}$ & $84(77,91)^{\mathrm{C}}$ \\
\hline Stevens ${ }^{\mathrm{d}}$ & $96.0(30.4)^{\mathrm{a}}$ & $-8.5(28.1)^{\mathrm{c}}$ & $-13.9,-3.1$ & $28.1^{\mathrm{c}}$ & $29(20,38)^{\mathrm{c}}$ & $75(66,83)$ \\
\hline Stevens ${ }^{\mathrm{e}}$ & $85.6(19.0)^{\mathrm{a}}$ & $-18.9(19.0)^{\mathrm{c}}$ & $-22.5,-15.2$ & 19.0 & $27(19,36)^{\mathrm{c}}$ & $78(70,86)$ \\
\hline
\end{tabular}

Isotopic GFR 104.5 (20.1) $\mathrm{ml} \mathrm{min}^{-1} 1.73 \mathrm{~m}^{-2}$

Data are shown as mean (SD) unless otherwise indicated

a $p<0.05$ for difference between isotopic GFR and estimated GFR

${ }^{\mathrm{b}}$ Mean difference between estimated GFR and isotopic GFR

${ }^{\mathrm{c}} p<0.05$ for difference in bias, precision and accuracy between cystatin C-and MDRD-estimated GFR

${ }^{\mathrm{d}}$ Cystatin $\mathrm{C}-$-age

${ }^{\mathrm{e}}$ Cystatin $\mathrm{C}$-creatinine

estimated GFR and isotopic GFR), precision (SD of the bias) and accuracy (proportion of estimated GFR results within $10 \%$ and $30 \%$ of isotopic GFR).

The MDRD formula significantly underestimated isotopic GFR. Underestimation was also observed using the formula proposed by Rule et al. [7] and both recent formulae proposed by Stevens et al. [10], while the formula proposed by Perkins et al. [4] significantly overestimated GFR. However, no statistically significant difference was seen between mean cystatin C-estimated GFR and isotopic GFR when using the formulae proposed by Arnal et al., MacIsaac et al. or Tan et al. $[6,8,9]$.

Without exception all cystatin C-based formulae were less biased than the MDRD formula with distinct $95 \%$ CIs being observed.

However, except for Stevens' (cystatin C-creatinine) formula [10], cystatin $\mathrm{C}$-estimated GFR values were less precise than the MDRD formulae $(p<0.05)$.

With regard to accuracy, the proportion of estimated GFR results within $10 \%$ of isotopic GFR was greater using cystatin C-based formulae (except with Perkins' formula [4]) than the MDRD formula, as evidenced by distinct $95 \%$ CIs. However, only the equations proposed by MacIsaac et al. and Tan et al. [8, 9] had a significantly greater proportion of results within $30 \%$ of isotopic GFR than the MDRD formula.

A regression formula, GFR $=138.7-39.8$ (cystatin C) $(r=0.462, p<0.0001)$, was derived from the relationship between isotopic GFR values and cystatin C-derived values. The relationship between cystatin $\mathrm{C}$ and isotopic GFR is shown in Fig. 1.

\section{Discussion}

GFR prediction is widely employed to screen for chronic kidney disease especially in high-risk groups such as persons with diabetes. Although validated for use in established chronic kidney disease [2], the MDRD has recognised limitations [3] and a tendency to underestimate GFR in patients who are free of chronic kidney disease. In

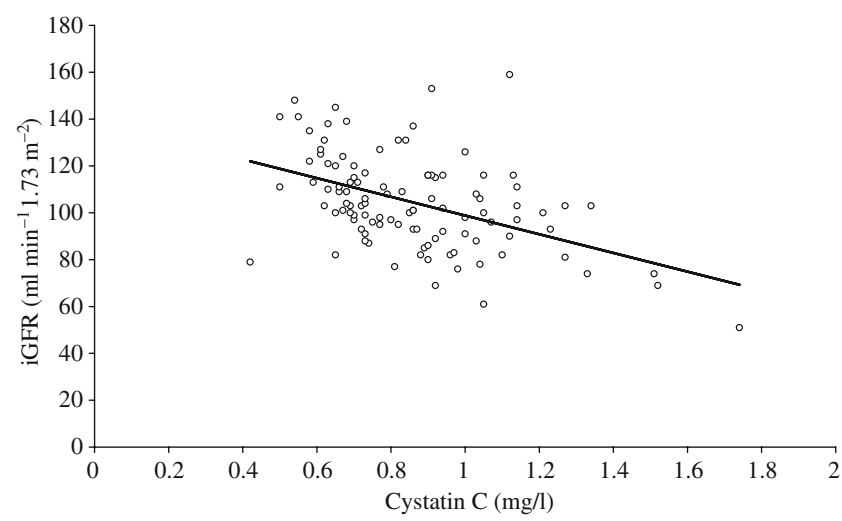

Fig. 1 Scatter plot of cystatin $\mathrm{C}$ vs isotopic GFR. Isotopic GFR= 138.7-39.8 cystatin $C, r=0.462$. The diagonal line represents the line of best fit for the relationship of cystatin $\mathrm{C}$ and isotopic GFR 
light of these deficiencies, interest has focused on novel markers of kidney function such as cystatin $\mathrm{C}$, and recently several formulae have been proposed, from which estimations of GFR can be made on the basis of cystatin C concentration. We examined a selection of these formulae and applied them to our own cohort of participants with type 2 diabetes and normoalbuminuria.

We have demonstrated that cystatin C-based estimations of GFR were generally less biased than those obtained using the MDRD formula. With the exception of Perkins' formula improved accuracy within $10 \%$ of isotopic GFR was seen with all of the cystatin $\mathrm{C}$ formulae when compared with the MDRD formula. However, only the equations proposed by MacIsaac et al. [8] and Tan et al. [9] were more accurate within $30 \%$.

The performance of cystatin C-based equations in our cohort is consistent with others who have demonstrated the superiority of cystatin $\mathrm{C}$ over other methods of estimating GFR [4, 5, 8, 9]. Consistent with MacIsaac [8] and coworkers, who studied a population of white patients with type 2 diabetes with a mean GFR of $88 \mathrm{ml} \mathrm{min}^{-1} 1.73 \mathrm{~m}^{-2}$, we demonstrated accuracy within $30 \%$ in over $80 \%$ of results, with a similar degree of bias. In our population, performance of the MDRD equation was less robust than in MacIsaac's cohort with greater bias and less accuracy being observed. This may reflect the higher mean isotopic GFR and lack of patients with chronic kidney disease in our group. Similarly to Perkins et al. [4], who studied patients with type 2 diabetes, we found that in our cohort the reciprocal of cystatin $\mathrm{C}$ tended to overestimate isotopic GFR.

Interestingly, the equations proposed by MacIsaac [8] and Tan [9], which were obtained in diabetic patients mainly free of chronic kidney disease, performed better than those of the MDRD group [2], and of Rule [7] and Stevens [10], which were developed in patients with established chronic kidney disease. This suggests that the relationship between cystatin C and GFR may be different in patients with chronic kidney disease than in those without chronic kidney disease.

When we derived a regression formula for isotopic GFR based on cystatin $\mathrm{C}$ values the $r$ values obtained were significantly lower than those of Rule, MacIsaac, Tan and Stevens [7-10], which may again reflect the absence of patients with established chronic kidney disease in our study.

Currently cystatin $\mathrm{C}$ is not widely used to assess kidney function, having not been extensively validated in different patient groups and at different stages of chronic kidney disease. Compared with serum creatinine, cystatin $\mathrm{C}$ is more expensive and there is also no standardised measurement of cystatin C. In our study, a colorimetric assay was used to measure cystatin $\mathrm{C}$, while other investigators have used immunonephelometric or turbidometric assays. Currently, standardisation of these different methods remains unresolved. However, the establishment of an international working group for standardisation of cystatin $\mathrm{C}$ measurements is under way. This body will seek to promote standardisation of cystatin $\mathrm{C}$ measurement through the definition of an international reference standard. In this context and with a view to defining normal ranges for adults, recent studies have also looked at distribution of cystatin $\mathrm{C}$ within the healthy population [12].

Emerging evidence supports the superiority of cystatin C over serum creatinine as a way to assess GFR [10]. Our work shows that cystatin $\mathrm{C}$ is a potential marker of kidney function in type 2 diabetic patients at risk of chronic kidney disease. However, further work is required to evaluate cystatin $\mathrm{C}$ as an indicator of kidney function in persons at risk of chronic kidney disease.

Duality of interest The authors declare that there is no duality of interest associated with this manuscript.

\section{References}

1. American Diabetes Association Position Statement. Standards of Medical Care in Diabetes (2009) Diabetes Care 32:S33-S34

2. Levey AS, Bosch JP, Lewis JB, Greene T, Rogers N, Roth D (1999) A more accurate method to estimate glomerular filtration rate from serum creatinine: a new prediction equation: Modification of Diet in Renal Disease Study Group. Ann Intern Med 130:461-470

3. Rossing P, Rossing K, Gaede P, Pedersen O, Parving HH (2006) Monitoring kidney function in type 2 diabetic patients with incipient and overt diabetic nephropathy. Diabetes Care 29:10241030

4. Perkins BA, Nelson RG, Ostrander BEP et al (2005) Detection of renal function decline in patients with diabetes and normal or elevated GFR by serial measurements of serum cystatin C concentration: results of a 4-year follow-up study. J Am Soc Nephrol 16:1404-1412

5. Premaratne E, MacIsaac R, Finch S, Panagiotopoulos S, Ekinci E, Jermus G (2008) Serial measurements of cystatin C are more accurate than creatinine-based methods in detecting declining renal function in type 1 diabetes. Diabetes Care 31:971-973

6. Beauvieux MC, Moigne Le, Lasseur C et al (2007) New predictive equations improve monitoring of kidney function in patients with diabetes. Diabetes Care 30:1988-1994

7. Rule AD, Bergstrahl EJ, Slezak JM, Bergert J, Larson TS (2006) Glomerular filtration rate estimated by cystatin C among different clinical presentations. Kidney Int 69:399-405

8. MacIsaac RJ, Tsalamandris C, Thomas MC et al (2006) Estimating glomerular filtration rate in diabetes: a comparison of cystatin C and creatinine based methods. Diabetologia 49:16861689

9. Tan GD, Lewis AV, James TJ, Altmann P, Taylor RP, Levy JC (2002) Clinical usefulness of cystatin $C$ for the estimation of glomerular filtration rate in type 1 diabetes. Reproducibility and 
accuracy compared with standard measures and iohexol clearance. Diabetes Care 25:2004-2009

10. Stevens LA, Coresh J, Schmid CH et al (2008) Estimating GFR using serum cystatin $\mathrm{C}$ alone and in combination with serum creatinine: a pooled analysis of 3, 418 individuals with CKD. Am J Kidney Dis 51:395-406
11. Vora JP, Burch A, Owens DR et al (1991) Simultaneous determination of glomerular filtration rate and effective renal plasma flow. Clin Phys Physiol Meas 12:269-277

12. Kottgen A, Selvin E, Stevens LA et al (2008) Serum cystatin C in the United States: the third National Health and Nutrition Examination Survey (NHANES III). Am J Kidney Dis 51:385-394 